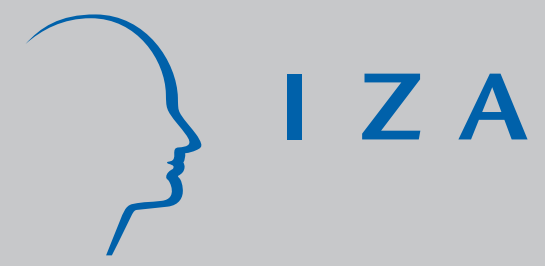

IZA DP No. 8649

Dual Labour Markets and (Lack of) On-the-Job Training: PIAAC Evidence from Spain and Other EU Countries

Antonio Cabrales

Juan J. Dolado

Ricardo Mora

November 2014 


\title{
Dual Labour Markets and (Lack of) On-the-Job Training: PIAAC Evidence from Spain and Other EU Countries
}

\author{
Antonio Cabrales \\ University College London \\ Juan J. Dolado \\ European University Institute \\ and IZA \\ Ricardo Mora \\ Universidad Carlos III de Madrid
}

Discussion Paper No. 8649

November 2014

\author{
IZA \\ P.O. Box 7240 \\ 53072 Bonn \\ Germany \\ Phone: +49-228-3894-0 \\ Fax: +49-228-3894-180 \\ E-mail: iza@iza.org
}

\begin{abstract}
Any opinions expressed here are those of the author(s) and not those of IZA. Research published in this series may include views on policy, but the institute itself takes no institutional policy positions. The IZA research network is committed to the IZA Guiding Principles of Research Integrity.

The Institute for the Study of Labor (IZA) in Bonn is a local and virtual international research center and a place of communication between science, politics and business. IZA is an independent nonprofit organization supported by Deutsche Post Foundation. The center is associated with the University of Bonn and offers a stimulating research environment through its international network, workshops and conferences, data service, project support, research visits and doctoral program. IZA engages in (i) original and internationally competitive research in all fields of labor economics, (ii) development of policy concepts, and (iii) dissemination of research results and concepts to the interested public.
\end{abstract}

IZA Discussion Papers often represent preliminary work and are circulated to encourage discussion. Citation of such a paper should account for its provisional character. A revised version may be available directly from the author. 
IZA Discussion Paper No. 8649

November 2014

\section{ABSTRACT}

\section{Dual Labour Markets and (Lack of) On-the-Job Training: PIAAC Evidence from Spain and Other EU Countries ${ }^{1}$}

Using the Spanish micro data from the Programme for the International Assessment of Adult Competencies (PIAAC), we first document how the excessive gap in employment protection between indefinite and temporary workers leads to large differentials in on-the-job training (OTJ) against the latter. Next, we find that that the lower specific training received by temporary workers is correlated with lower literacy and numeracy scores achieved in the PIAAC study. Finally, we provide further PIAAC cross-country evidence showing that OJT gaps are quite lower in those European labour markets where dualism is less entrenched than in those where it is more extended.

JEL Classification: C14, C52, D24, J24

Keywords: dual labour market, on-the-job training, cognitive skills, severance pay

Corresponding author:

Juan J. Dolado

Department of Economics

European University Institute

Via della Piazzola, 43

50133 Florence

Italy

E-mail: juan.dolado@eui.eu

\footnotetext{
${ }^{1}$ We are grateful to Andrea Bassanini, Roman Fossati, Andrea Ichino, Greg Jolivet, Stepan Jurajda and Helene Turon, as well as participants in the CAGE conference on "Education, Human Capital and Labor Market Outcomes" (Venice), ESSLE 2014 (Ammersee) and seminars at EUI and Bristol for useful comments that improved the paper. We also wish to thank Nicolas Escribano for excellent research assistance.
} 


\section{INTRODUCTION}

This paper analyzes whether the gap between the amount of employer-sponsored training for permanent workers (those holding an indefinite/permanent contract) and temporary workers (those holding a fixed-term contract) is larger in dual labour markets than in a less segmented ones. One plausible mechanism leading to this gap relies on the large turnover rate among temporary workers induced by the much less stringent employment protection legislation (EPL henceforth) they enjoy relative to permanent workers. Given this EPL differential, whenever collective bargaining prevents neutralizing severance pay (i.e., a transfer from employers to workers) through enough wage flexibility, firms will prefer to use temporary contracts in sequence rather converting them into permanent contracts. As a result, the expected job duration of temporary workers becomes too short, therefore making firms more reluctant to invest in their training. By contrast, the much more stringent EPL enjoyed by permanent workers increases their expected job duration, making firms more eager to invest in them. Thus, in dual labour markets, lower on-the-job training (OJT hereafter) attached to temporary contracts might be one of the main reasons why these contracts become dead ends, in contrast to stepping stones, like in labour markets where the EPL gap is smaller.

Besides exploring this channel, we are also interested in analyzing whether the occupational training gap may also translate into persistent differences in workers' cognitive skills. To the extent that training at the workplace helps accumulating skills, dualism in the labour market may not only hinder the specific human capital of temporary workers but also their general human capital. ${ }^{2}$ This is a topic of considerable importance for policy in countries like Spain which traditionally has been considered as a paradigmatic case study of a highly segmented labour market (see OECD 2014). For this reason, we provide empirical evidence mainly for this country. Yet, in order to check whether the mechanism operates in other labour markets, we also provide some evidence comparing the findings for Spain with those for a small group of reference EU countries, used as a benchmark. The chosen set of countries is such that some also have dual labour markets (France and Italy) while others have rather more unified labour markets (Denmark and UK).

Regarding Spain, two of the most salient features of its labour market over the last few decades have been: (i) a strong segmentation stemming from large differences in EPL that encouraged the widespread use of temporary contracts, and (ii) a rather low fraction of workers receiving OJT.

\footnotetext{
${ }^{2}$ As Acemoglu and Pischke (1999) have pointed out, it might be the case that, when labour market frictions compress the wage structure, employer-sponsored training includes financing of investment in human capital. Thus, OJT affects both specific and general human capital, explaining in this way their relationship between both types of human capital. However, in dual labour markets where worker turnover rate is very large, the underlying argument in the reasoning above (monopsony power enjoyed by the firm) seems less compelling.
} 
The origin of the first feature dates back to 1984 when a radical labour market reform was passed to ameliorate the surge in unemployment after the restoration of democracy when the Spanish economy was hit by the second oil price crisis. This reform allowed the indiscriminate use of temporary contracts (with either reduced or no costs for dismissal) for any regular productive activity (not just for seasonal employment, as it had been the case until then), while keeping unchanged the rigid EPL of permanent contracts inherited from four decades of industrial relations under a military dictatorship (see, e.g., Dolado et al., 2002 and 2008).

The rate of temporary work (i.e., the share of employees under temporary contracts) soared from $15 \%$ just before the reform to $35.4 \%$ in the mid-nineties. Since then, around $90 \%$ (94\% nowadays) of newly signed contracts have been temporary ones, while the average temp-toperm conversion rate has ranged between $10 \%$ in the nineties and first half of the 2000 s and 6\% nowadays (see Amuedo-Dorante, 2001 and Güell and Petrongolo, 2007). Later on, as a result of a long sequence of partial labour market reforms, the rate of temporary work stabilized around $30 \%$. More recently, even after the mass destruction of temporary jobs in Spain during the Great Recession, it has only dropped to $24 \%$ since 2009 , which still remains as one of the highest rates in the OECD.

As regards the second feature, although the participation of workers in OJT has increased from $10 \%$ in the early nineties to $24 \%$ in 2010 , this rate, together with the Italian one, remains one of the lowest in the EU-27 being 8 pp. below the EU average rate and between 20-30 pp. lower than in Scandinavian countries or the UK (see European Commission, 2014). Figure 1 displays the transition rates from temporary to permanent contracts (vertical axis, in percent), as a measure of segmentation in labour markets, and the proportion of employees participating in OJT (horizontal axis, in percent) in several EU countries in 2010. As can be observed, there is a strong positive correlation between both variables, indicating that in those countries where temporary contracts are a springboard to better and more stable jobs (higher transition rates) the fraction of employees participating in OJT schemes is larger.

Figure 1. Temp-to perm transition rates and OJT participation 
Our aim in this paper is to analyze the relationship between these two features, focusing on the mechanism sketched above which so far has received scarce attention in the literature. To provide empirical evidence on this mechanism, use will be made of the cross-sectional database available for Spain and the other reference countries in the recently released first wave of the Survey of Adult Skills, the main output of the Programme for the International Assessment of Adult Competencies (PIAAC, 2013). As will be discussed later on, PIAAC provides harmonized and updated information on the availability of OJT at individual level in a large number of countries, as well as a wide array of demographics and job characteristics, including type of contract.

As mentioned earlier, the basic insight of our approach is that temporary contracts in dual labour markets no longer play the role of being "probationary contracts" (stepping stones). They rather become "terminal contracts" (dead-ends) leading to a very high worker turnover between employment and unemployment. As a result, firms have little incentive to invest in training those employees with temporary contracts. By the same token, workers lack the right incentives to improve on their job performance by accumulating better productive capabilities. Further, since these skills and OJT are important components of multifactor productivity, this mechanism may have played a relevant role in explaining the unsatisfactory development of TFP growth in Spain and other EU countries with segmented labour markets (see Bassanini et al., 2009).

This type of mechanism has been recently explored by Dolado et al. (2013) in a model where the decisions of employers and workers interact in a dual labour market akin to the Spanish one. The setup is one in which firms find it optimal to hire workers initially under fixed-term contracts. When such contracts expire (typically after one year), the employers face the decision to upgrade the worker to a permanent contract (subject to much larger firing costs) or to dismiss the worker and hire in sequence another one on a temporary basis. Their main result is that, by severely reducing the temp-to-perm conversion rate, an increase in the EPL gap leads to lower TFP growth. The basic insight is that employers do not find it profitable to invest in training temporary workers who are very unlikely to continue in the firm. This also gives rise to a discouragement effect among these workers, who respond to the lower and more uncertain promotion prospects by exerting lower effort. Further, given that temporary contracts are much more flexible, firms specialize in mature technologies which are not very innovative (e.g., construction and tourism). Hence, this setup leads to self-fulfilling prophecies where employers do not invest in workers, expecting that they will not exert enough effort, and workers fulfill these expectations by rationally anticipating low promotion prospects.

To test the main predictions of the model, Dolado et al. (2013) use firm-level longitudinal information on a representative sample of manufacturing firms in Spain during 1991-2005. This allows them to compute TFP growth rate and the conversion rate of temporary workers into permanent ones for each year and firm in their database. By means of panel regression methods, their main empirical finding is that changes in the EPL gap are inversely related to conversion rates which in turn are positively correlated with their TFP growth rates.

In this paper we extend their analysis by focusing on one of the key outcome variables in their mechanism, namely firm-provided training. To do so, we use information drawn from PIAAC 
which provides different measures of OJT activities undertaken by employees. Further, the availability of PIAAC scores in the literacy and numeracy tests allows us to explore whether OJT affects workers' proficiency.

In order to derive the main testable hypotheses in our empirical approach, we start by laying out a simple two-period model of OJT provision in a dual labour market. At the beginning of the first period, individuals with different innate abilities are randomly assigned to firms with identical technologies. With equal probability workers are hired either under permanent contracts (with high dismissal costs) or under temporary contracts (with low or even no dismissal costs and shorter expected job duration). During the initial period, firms decide whether to offer training in order to improve workers' productivity in the second period. To do so they face a cost of providing OJT that is decreasing in the individual's innate ability. However, due to aggregate productivity shocks and the sudden termination of fixed-term contracts, some of these jobs get destroyed during the second period. In the absence of wage flexibility, severance pay implies that, when hit by a shock, firms offering permanent contracts will find it optimal to dismiss less workers than those offering temporary contracts (see Cahuc and Postel-Vinay, 2002, and Bentolila et al., 2012). Hence, firms with permanent jobs will face a trade-off between paying dismissal costs and having longer job duration. We show that, under some plausible conditions regarding wage rigidity, a large EPL gap leads to a higher provision of OJT to permanent workers and to the same or even lower supply of OJT for temporary workers.

Overall, our empirical results support this prediction. First, using a large array of controls on individual and job characteristics (including worker's motivation) both in standard regression analysis and propensity score matching estimation, we find a substantially negative and statistically significant relationship between holding a temporary contract and the amount of OJT received at the workplace. Secondly, we find that the less OJT individuals receive, the worse their literacy and numeracy skills. These results turn out to be consistent with the growing empirical evidence about the negative effects of persistent labour market dualism in Spain on productivity growth and unemployment (see Bentolila et al., 2012). Moreover, we provide similar evidence for other EU countries with dual labour markets while the evidence is much weaker or non-existent for countries with more unified labour markets.

The rest of the paper is structured as follows. Section 2 provides a brief overview of the related literature in Spain on this topic. Section 3 develops a simple theoretical model that guides our empirical approach. Section 4 describes the PIAAC database and provides descriptive statistics of the outcome and treatment variables used in the empirical analysis for Spain. Section 5 presents the main empirical results for this country. Section 6 reports the evidence for the reference EU countries. Finally, Section 7 draws some brief conclusions. 


\section{ReLATED LiteratuRE}

In addition to the previously discussed paper by Dolado et al. (2013), there are some other related works focused on the Spanish case that examine the effects of segmentation in the labour market on productivity growth and training. We next summarize their main conclusions.

Possibly the first paper addressing this issue is Sánchez and Toharia (2000) who, on the basis of the main implications of a standard efficiency wage model, use data from the Survey of Business Strategies (SBS) for the period 1991-1994 to estimate the relationship between the rate of temporary work and labour productivity growth. Specifically, they regress average labour productivity on the rate of temporary work at the firm level, plus other controls, finding a negative relationship between both variables. Similar results been obtained by AlonsoBorrego (2010) and Gonzalez and Miles (2012) using the Firms' Balance Sheets of the Bank of Spain (CBBE) and the SBS, respectively. Like Dolado et al. (2013), these authors focus on documenting the negative effect of contractual instability on TFP growth. Yet, they do not deal with the mechanism linking conversion rates and TFP which is stressed by the latter authors.

Regarding the relationship between dualism and the incidence of occupational training in Spain, it is worth highlighting the work of Alba-Ramirez (1994) and De la Rica et al. (2008). In both cases, they document that firms invest less in training temporary workers given their high turnover rates. However, they do not examine how the amount of training has varied with the changes observed in the EPL gap. This result is also in line with the findings by Arulampalam et al. (2004) that Spain is one of the countries where being on a fixed-term contract is associated with lower training, in their cross-country study on the determinants of training using the European Community Household Panel (ECHP) over the period 1994-1999.

Lastly, Garda (2013) has recently analyzed the size of wage losses experienced by those workers who have been displaced to other firms as a result of having been subject to a collective dismissal (ERE) in their previous firm. If firms provide a higher level of specific training to workers with permanent contracts than to those with temporary contracts, the loss of this type of human capital will be more significant for the first type of workers than for the second. Therefore, we would expect to find higher wage losses among workers with permanent contracts. Using the Social Security records from the Continuous Sample of Working Lives (MCVL) and controlling by job tenure, sector of activity and other covariates, the results confirm that permanent workers subject to EREs suffer higher and more permanent wage cuts than those with temporary contracts. 


\section{A Model of OJT in a Dual Labour Market}

\subsection{Preliminaries}

In our stylized model, inspired by Lepage-Saucier et al. (2013), workers and firms live for two periods and, for simplicity, there is no time discounting. At the beginning of the first period, individuals get hired by firms in a framework where each firm hires one worker and where, for simplicity, hiring costs are set equal to zero. Hiring takes place whenever the asset values of such a decision for the firm, $W$, and for the worker, $V$, are non-negative. Firms have a simple linear production technology where output equals the workers' $s$ level of human capital, which coincides with their productivity. Human capital is taken to be a composite of the individual's innate ability and firm-specific OJT, whose role is to raise workers' productivity. The initial ability of the worker, $\theta$ is assumed to be uniformly distributed with support $[\underline{\theta}, \bar{\theta}]$. We assume that there are only two levels of OJT, i.e., one involving no training and another where some fixed amount of training is provided. Thus, under these simplifying assumptions, human capital/ productivity of untrained (superscript $u$ ) and trained (superscript $t$ ) workers are given by $H^{u}(\theta)=\theta$ and $H^{t}(\theta)=h \theta$, with $h>1$, respectively.

OJT takes place in the first period and it is assumed that the return for the firm of such investment only accrues during the second period. While untrained workers produce $\theta$ in each of the two periods, trained workers bear a loss of productivity in the first period (due to their enrolment in OJT activities) in exchange for a higher productivity in the second period. Thus, the initial productivity of a trained worker is given by $\theta-C(\theta)$, where $C(\theta)$ is the cost in terms of output loss entailed by undertaking OJT. This cost is assumed to be decreasing in ability, i.e. $C^{\prime}(\theta)<0$. For illustrative purposes, in the sequel we choose the simple functional form $C(\theta)=k(\bar{\theta}-\theta)$, with $k>0$ implying that the output loss is null for a worker with the highest ability type $\bar{\theta}$. As a result, the initial productivity of a trained worker becomes $\theta-k(\bar{\theta}-\theta)$, while it increases to $h \theta(>\theta)$ in the second period. ${ }^{3}$

Although all firms have the same technology, some of them hire workers under temporary $(T)$ while others do under permanent contracts $(\mathrm{P})$. For simplicity, it is assumed that workers are offered either type of contract with the same probability. ${ }^{4}$ The difference between the two types of contracts is that dismissing a worker with a permanent contract involves mandated severance pay $F>0$ whereas destroying a temporary job does not involve any dismissal cost. Thus, $F$ could be interpreted in the sequel as the EPL between permanent and temporary workers. Furthermore, to capture in a simple way the unstable nature of temporary contracts--

2. Notice that our simple formulation of the OJT costs paid by the firm implies that the net productivity of a trained worker is negative for values of $\theta$ low enough, namely when $\theta<(k / 1+k) \bar{\theta}$, meaning that these workers will not be trained.

4 We abstain from modeling the supply of $P$ and $T$ contracts by firms because our interest lies in the training decisions by employers with similar technologies about workers with similar skills. An attempt to model the relative supply of both types of contracts can be found in Bentolila et al. (2012). 
because of their short-term duration or low rate of conversion into indefinite contracts-- a key assumption is that temporary workers quit their jobs during the second period at rate $q$, with $0<q<1$, while permanent workers will never quit. This implies a trade-off between permanent and temporary contracts because the surplus going to the firm is negatively affected by $F$ in a permanent contract and by $q$ in a temporary one.

To account for endogenous job destruction we follow the standard Mortensen-Pissarides modeling device by assuming that productivity diverges during the second period due to an aggregate shock. In particular, during this period, productivity for untrained workers is perceived by firms to be uniformly distributed $U[\bar{\theta}(1-\varepsilon), \bar{\theta}]$, where $\varepsilon \in(0,1)$ is a parameter of the distribution, for which it holds that $\underline{\theta}=\bar{\theta}(1-\varepsilon)$. As a result, during the second period, the p.d.f. and c.d.f. of productivity for this type of worker become $g_{\theta}(\varepsilon)=\frac{1}{\varepsilon \bar{\theta}}$ and $G_{\theta}(\varepsilon)=1+\frac{\theta-\bar{\theta}}{\varepsilon \bar{\theta}}$, respectively. As for trained workers, the corresponding distribution is $U[\bar{\zeta}(1-\varepsilon), \bar{\zeta}]$, where $\bar{\zeta}=h \bar{\theta}$, so that $g_{\zeta}(\varepsilon)=\frac{1}{\varepsilon \bar{\zeta}}$ and $G_{\zeta}(\varepsilon)=1+\frac{\zeta-\bar{\zeta}}{\varepsilon \bar{\zeta}}$. Notice that in both cases a higher (lower) value of $\varepsilon$ should be interpreted as capturing a recessionary (expansionary) period in the business cycle during where the average productivity of workers in both types of firms drops (increases).

The wage paid in $\mathrm{P}$ and $\mathrm{T}$ jobs is assumed to be the same and is denoted as $W$. We take a partial equilibrium approach by assuming that the wage is determined exogenously and that it is rigid. ${ }^{5}$ Specifically, the exogenous wage is posted by the firms at the beginning of the first period but is only paid in the second period to those workers who have not been dismissed or have not quit. Further, it is assumed that the value of the exogenous wage verifies the inequality $F<w<\bar{\theta}$. As will be shown below, this range of the wage ensures that individuals always prefer working to not working so that the participation constraints are satisfied.

Summing up, the sequence of events in this economy can be summarized is as follows.

1. In period 1, firms decide how much training to offer to each worker hired at a given wage $w$ (paid in period 2) and knowing their ability $\theta$.

2. At the end of period 1 , a temporary worker quits with probability $q$.

3. At the beginning of period 2, an aggregate shock takes place and some workers are dismissed. Permanent workers receive mandated severance pay $F$ while temporary workers receive none.

4. At the end of period 2, retained workers receive the wage $w$.

\footnotetext{
${ }^{5}$ We adopt this strategy to simplify the analysis but it can be shown that assuming some dependence of wages on productivity does not change the results though it makes the algebra more complicated.
} 


\subsection{Asset values}

\section{(I) Firms}

As discussed earlier, firms hire workers whenever the expected value of their contribution to the firm's profits is greater to be zero for both types of jobs.

Denote by $W_{i}^{t}$ and $W_{i}^{u}(i=P, T)$ the asset values for firms of having trained and untrained workers, respectively, in either type of job. Then, using integration by parts (see Appendix), the asset values for firms with $\mathrm{P}$ jobs are given by,

$$
\begin{aligned}
& W_{P}^{t}(\varepsilon, \zeta)=\theta-k(\bar{\theta}-\theta)+\left[\int_{\bar{\zeta}(1-\varepsilon)}^{\bar{\zeta}} \max (\zeta-w,-F) d G_{\zeta}(\varepsilon)\right]= \\
& =\theta-k(\bar{\theta}-\theta)+\left[(\bar{\zeta}-w)-\int_{w-F}^{\bar{\zeta}} G_{\zeta}(\varepsilon) d \zeta\right], \\
& W_{P}^{u}(\varepsilon, \theta)=\theta+\left[\int_{\bar{\theta}(1-\varepsilon)}^{\bar{\theta}} \max (\theta-w,-F) d G_{\theta}(\varepsilon)\right]= \\
& =\theta+\left[(\bar{\theta}-w)-\int_{w-F}^{\bar{\theta}} G_{\theta}(\varepsilon) d \zeta\right]
\end{aligned}
$$

By the same reasoning, the asset values for firms offering temporary jobs become,

$$
\begin{aligned}
& W_{T}^{t}(\varepsilon, \zeta)=\theta-k(\bar{\theta}-\theta)+(1-q)\left[\int_{\bar{\zeta}(1-\varepsilon)}^{\bar{\zeta}} \max (\zeta-w, 0) d G_{\zeta}(\varepsilon)\right]= \\
& =\theta-k(\bar{\theta}-\theta)+(1-q)\left[(\bar{\zeta}-w)-\int_{w}^{\bar{\zeta}} G_{\zeta}(\varepsilon) d \zeta\right] \\
& W_{T}^{u}(\varepsilon, \theta)=\theta+(1-q)\left[\int_{\bar{\theta}(1-\varepsilon)}^{\bar{\theta}} \max (\theta-w, 0) d G_{\theta}(\varepsilon)\right]= \\
& =\theta+(1-q)\left[(\bar{\theta}-w)-\int_{w}^{\bar{\theta}} G_{\theta}(\varepsilon) d \theta\right] .
\end{aligned}
$$

Note that the terms $w-F$ and $w$ in (1) to (4) turn out to be the reservation productivity cutoffs in $\mathrm{P}$ and $\mathrm{T}$ jobs, respectively, so that workers with productivities below these cutoffs will see their contracts terminated in the second period. Notice that a higher value of $F$ reduces the productivity cutoff for $\mathrm{P}$ workers since, having to pay dismissal costs, firms will 
prefer not to sack workers with lower productivity. In particular, using the uniform distributions $\zeta \sim U[h \bar{\theta}(1-\varepsilon), h \bar{\theta}]$ and $\theta \sim U[\bar{\theta}(1-\varepsilon), \bar{\theta}]$ with $\varepsilon \in(0,1)$ yields,

$$
\begin{aligned}
& W_{P}^{t}(\varepsilon, \varsigma)=\theta-k(\bar{\theta}-\theta)+\left[\frac{(h \bar{\theta}-w+F)^{2}}{2 \varepsilon h \bar{\theta}}-F\right] \\
& W_{P}^{u}(\varepsilon, \theta)=\theta+\left[\frac{(\bar{\theta}-w+F)^{2}}{2 \varepsilon \bar{\theta}}-F\right], \\
& W_{T}^{t}(\varepsilon, \varsigma)=\theta-k(\bar{\theta}-\theta)+(1-q)\left[\frac{(h \bar{\theta}-w)^{2}}{2 \varepsilon h \bar{\theta}}\right] . \\
& W_{T}^{u}(\varepsilon, \theta)=\theta+(1-q)\left[\frac{(\bar{\theta}-w)^{2}}{2 \varepsilon \bar{\theta}}\right] .
\end{aligned}
$$

\section{(II) Workers}

Normalizing the value of being unemployed to zero for simplicity, we next derive the asset values of workers, denoted by $V_{i}$, in $\mathrm{P}$ and $\mathrm{T}$ contracts. We start with those pertaining to trained workers, which yields,

$$
\begin{aligned}
& V_{P}^{t}(\varepsilon, \varsigma)=\left[\int_{w-F}^{\bar{\zeta}} w d G_{\zeta}(\varepsilon)+\int_{\bar{\zeta}(1-\varepsilon)}^{w-F} F d G_{\zeta}(\varepsilon)\right]= \\
& =\frac{(w-F)[h \bar{\theta}-(w-F)]}{\varepsilon h \bar{\theta}}+F \\
& V_{T}^{t}(\varepsilon, \varsigma)=(1-q) \int_{w}^{\bar{\zeta}} w d G_{\zeta}(\varepsilon)= \\
& =(1-q)\left[\frac{w(h \bar{\theta}-w)}{\operatorname{ch} \bar{\theta}}\right]
\end{aligned}
$$

The asset values for untrained workers in $\mathrm{P}$ and $\mathrm{T}$ jobs, $V_{P}^{u}(\varepsilon, \theta)$ and $V_{T}^{u}(\varepsilon, \theta)$, are similar to (9) and (10) but with $\bar{\theta}$ replacing $\bar{\zeta}$ in the expression above. Thus, given that $h>1$, the assumed inequality for wages, namely $F<w<\bar{\theta}$ (and hence $h \bar{\theta}-(w-F)>0$ ) imply that the asset values of workers are all positive and therefore that their participation constraints are satisfied. 


\subsection{Decisions on OJT}

Using the previous asset values of firms in (5) to (8) we can now compute the ability threshold values, denoted by $\theta^{*}$, determining whether firms provide OJT to their workers. In our model this is the key decision variable taken by firms. As regards workers hired under permanent contract, firms would find it profitable to offer them training whenever,

$$
\begin{aligned}
& W_{P}^{t}(\varepsilon, \varsigma) \geq W_{P}^{u}(\varepsilon, \theta) \\
& \Leftrightarrow \theta-k(\bar{\theta}-\theta)+\left[\frac{(h \bar{\theta}-w+F)^{2}}{2 \varepsilon h \bar{\theta}}-F\right] \geq \theta+\left[\frac{(\bar{\theta}-w+F)^{2}}{2 \varepsilon \bar{\theta}}-F\right] \\
& \Leftrightarrow \theta \geq \theta_{P}^{*} \equiv \bar{\theta}-\frac{(h-1)}{2 k \varepsilon h \bar{\theta}}\left[h \bar{\theta}^{2}-(w-F)^{2}\right]
\end{aligned}
$$

where $\theta_{P}^{*}$ is the ability threshold above which firms with $\mathrm{P}$ jobs will offer OJT to their workers. Since it is a lower bound, notice that OJT varies inversely with $\theta_{P}^{*}$, namely, the lower $\theta_{P}^{*}$ the higher the OJT intensity. From (11) it can be observed that, not surprisingly, OJT declines with its cost $(k)$ and increases with its return $(h)$. More interesting is the result that, for a given wage, OJT for permanent workers increases with the firing-cost gap $F$. The insight is that, as firing cost go up, workers' job stability increases since lower productivity workers are less likely to be dismissed. This induces a longer expected horizon for the firm to recoup its initial investment on OJT.

Using a similar reasoning we can derive the ability threshold for temporary workers, such that,

$$
\begin{aligned}
& W_{T}^{t}(\varepsilon, \varsigma) \geq W_{T}^{u}(\varepsilon, \theta) \\
& \Leftrightarrow \theta-k(\bar{\theta}-\theta)+(1-q)\left[\frac{(h \bar{\theta}-w)^{2}}{2 \varepsilon h \bar{\theta}}\right] \geq \theta+(1-q)\left[\frac{(\bar{\theta}-w)^{2}}{2 \varepsilon \bar{\theta}}\right] \\
& \Leftrightarrow \theta \geq \theta_{T}^{*} \equiv \bar{\theta}-\frac{(h-1)}{2 k c h \bar{\theta}}(1-q)\left[h \bar{\theta}^{2}-w^{2}\right]
\end{aligned}
$$

where $\theta_{T}^{*}$ is the corresponding ability threshold above which firms with T jobs provide OJT to their workers. As before, OJT is decreasing in $k$ and increasing in $h$. Yet, OJT decreases as $q$ increases since a higher quit rate implies more job instability and therefore a shorter expected duration for the firm to recover the OJT investment on the worker.

A comparison of $\theta_{P}^{*}$ and $\theta_{T}^{*}$ immediately reveals that individuals holding temporary contracts will unambiguously receive less training than under a permanent contract as long as $F>0$. In effect, this result holds whenever $\theta_{P}^{*}<\theta_{T}^{*}$ which is equivalent to $\left[h \bar{\theta}^{2}-(w-F)^{2}\right]>(1-q)\left[h \bar{\theta}^{2}-w^{2}\right]$. Given our assumption that firms pay the same wage for both types of contract and the allowed range of variation of this wage, the previous inequality always holds. Moreover, the higher the value of $F$ (i.e., the more dual is the labour market) the higher the OJT gap. Finally, if following the arguments by Dolado et al. (2013) on 
how an increase in the firing-cost gap is likely to reduce the temp-to-perm transformation rate (a decision by the firm which is not modeled here), we take the shortcut of assuming that $q$ is increasing in $F$, i.e., $q^{\prime}(F)>0$, higher $F$ will increase the OJT gap by more than before because permanent workers get more training while temporary workers get less.

\section{DATASET AND VARIABLES}

The population of interest is defined by those individuals aged 16- 65 who participated in the Spanish section of the Survey of Adult Skills (PIAAC) and had the status of employees in the private sector at the time of the survey. Out of the 6055 individuals who fully responded to the questionnaires, the sample size of those who are employees is reduced to about 2500 individuals.

Our main control variable, temporary contract, is a dummy variable that takes value 1 when the contract is a temporary one (defined in PIACC as having a fixed-term contract, temporary employment with an employment agency, or some kind of training contract) and value 0 when the employee holds a permanent contract.

As argued earlier, our empirical approach consists of two stages. First, we focus on testing whether holding a temporary contract is associated with a lower propensity of being involved in training activities provided by the firm. Next, we analyze how the amount of and intensity of training affects the employees' human capital, approximated by literacy and numeracy skills according to the scores available in the PIAAC database.

To empirically evaluate whether these predictions hold, we consider as training outcomes two proxies of specific human capital accumulation at the workplace. First, we use a dummy variable, $D^{O J T}$, which takes the value 1 if the worker claims to have attended a training session organized in the workplace or provided by their supervisors or colleagues in the past 12 months, and 0 otherwise. Thus, this variable captures the extensive margin of OJT. According to PIAAC, these training sessions should be characterized "by planned periods of training, instruction or practical experience, using the normal methods of work." For example, they include "training or instruction courses organized by the directors, managers or colleagues to help the respondent to do their job better or to familiarize them with their new tasks."

To capture the intensive margin of OJT, we use an additional outcome variable which measures the number of training activities attended by the worker during the past 12 months, denoted as $n^{\text {OJT }}$. It should be noted that, in accordance with the design of the survey, the respondent should count all training tasks that are interrelated as a single activity, even if they have taken place on different days,. The essential feature of each activity is that it should be designed "to facilitate the adaptation of personnel to a particular set of new competences". 
Therefore, the variable $n^{\text {OJT }}$ reflects the intensity of investment in new competences regardless of their level of difficulty or the time that has been devoted to each one of them. ${ }^{6}$

According to our theoretical reasoning, workers under temporary contracts receive less OJT than permanent workers those with permanent contracts. Yet, an interesting feature which has not been explicitly considered in our model is that, despite receiving less training, temporary workers may not perceive this as a problem since their skills requirements on these jobs could be low in general. The PIACC database allows us to explore this issue through the availability of a subjective measure of workers' demand of higher OJT. In particular, we use a dummy variable, denoted as more ${ }^{O J T}$, which takes the value 1 if the worker claims that she needs more training to perform her job tasks properly, and 0 if otherwise.

It is plausible that differences in the training processes within the firm generate differences in workers' promotion opportunities to reach better contracts. However, the extent to which these differences in specific human capital accumulation could lead to differences in general human capital remains an open question. To address this issue, we analyze the effect of OTJ activities on the two measurements of general cognitive skills reported in the Spanish PIAAC sample, namely, the scores achieved on the literacy and numeracy tests.

Table 1 presents descriptive statistics of the main outcome variables in the subsequent empirical analysis, i.e., the availability and intensity of OTJ activities, the perception on the efficacy of the training process and, finally, the scores in both tests. At first sight, the results of Table 1 are fairly consistent with the basic predictions of the model. As can be observed, temporary workers undertake less training activities than permanent workers. This finding is robust both in the extensive margin (i.e., using $D^{O J T}$ as a measure of the availability of training) and the intensive margin (i.e., using $n^{\text {OJT }}$ as a measure of the intensity of training). Further, in line with our previous conjecture, the results for more ${ }^{O J T}$ suggest that the reduced OJT of temporary workers does not translate into a greater demand of extra training. Finally, both literacy and numeracy scores are significantly lower among temporary workers.

3. PIAAC also provides a subjective measurement that reflects to some degree the intensity with which the worker acquires new skills in the job. In the survey, workers are asked to indicate, approximately, the frequency with which their job involves learning new skills. Besides the problem of interpretation often encountered with such subjective statements, this variable does not have enough variation to be really informative: over $90 \%$ of respondents reply that their job involves learning new skills "at least once a month." For these reasons, we have decided to discard it in this study. 
Table 1. Descriptive Statistics (PIAAC)

\begin{tabular}{|c|c|c|c|c|c|}
\hline Panel A & No. Obs. & $\begin{array}{l}\text { Pop. } 16-65 \\
\text { years }^{\text {(a) }}\end{array}$ & Employed $^{(a)}$ & Employees $^{(a)}$ & \\
\hline PIAAC sample & 6055 & & & & \\
\hline $\begin{array}{l}\text { Sample with ages between } \\
16 \text { and } 65 \text { years old }\end{array}$ & 5954 & & & & \\
\hline Type of workers & 3060 & 53.18 & & & \\
\hline Self-employed & 547 & 9.41 & 17.69 & & \\
\hline Employee & 2513 & 43.77 & 82.31 & & \\
\hline Temporary & 589 & 9.71 & 18.26 & 22.18 & \\
\hline Panel B & \multicolumn{2}{|c|}{$\begin{array}{l}\text { Training and abilities by type } \\
\text { of contract }^{(\mathrm{a})}\end{array}$} & Difference (\%) & Stand. Dev. ${ }^{(b)}$ & P-value \\
\hline & Permanent & \multicolumn{3}{|l|}{ Temporary } & \\
\hline $\begin{array}{l}\text { Percentage of employees } \\
\text { with training activities }\end{array}$ & 48.43 & 31.81 & $16.62(52.25)$ & 2.35 & 0.000 \\
\hline $\begin{array}{l}\text { Average number of } \\
\text { activities }\end{array}$ & 2.85 & 2.23 & $0.62(22.32)$ & 0.29 & 0.053 \\
\hline $\begin{array}{l}\text { Percentage which believes } \\
\text { it needs training }\end{array}$ & 39.55 & 35.42 & $4.13(11.66)$ & 2.48 & 0.096 \\
\hline Index of literacy ${ }^{\text {(c) }}$ & 262.68 & 255.63 & $7.05(2.76)$ & 2.10 & 0.001 \\
\hline \multirow[t]{2}{*}{ Index of numeracy ${ }^{\text {(c) }}$} & 260.94 & 246.81 & $14.13(5.73)$ & 2.00 & 0.000 \\
\hline & $D^{O J T}=1$ & $D^{O J T}=0$ & & & \\
\hline Index of reading literacy ${ }^{\text {(c) }}$ & 268.89 & 254.69 & $14.20(5.58)$ & 1.51 & 0.000 \\
\hline Index of numeracy ${ }^{\text {(c) }}$ & 268.09 & 249.44 & $18.65(7.48)$ & 1.49 & 0.000 \\
\hline \multicolumn{6}{|c|}{$\begin{array}{l}\text { Notes: A worker has a temporary contract when he/she has a fixed-term contract, a temporary job with a temporary work agency or any type of training contract. } D^{0} \\
\text { takes the value } 1 \text { when the worker claims to have attended training activities in the last } 12 \text { months, and } 0 \text { in the opposite case. The indices of literacy and numeracy } \\
\text { measurements attributed from the responses to exercises which are part of the survey. Literacy measures the ability to understand and use texts (written or in a digit } \\
\text { format) in different contexts, while numeracy measures the use, application, interpretation and communication of mathematical information and ideas. } \\
\text { (a) } \\
\text { (b) Uercentages of population estimated using weights of the whole sample as weightings. } \\
\text { (c) Uning the replication method Jk1. }\end{array}$} \\
\hline
\end{tabular}

However, it is important to stress that the negative relationship found between temporary contracts and OTJ activities does not necessarily imply causality. In particular, the results in Table 1 do not allow us to state that workers accumulate less specific human capital in the firm because their contract is a temporary one. The main reason for why this may be a misleading conclusion is that both the type of contract and training activities could be jointly affected by other variables. For example, consider a worker with a high level of motivation to perform well in the job. Then, precisely because of this feature, this individual could influence his/her employer to obtain a permanent contract and freely choose to participate intensively in OJT activities. In that case, we would observe a positive correlation between having a permanent contract and participation in training activities but the intense process of accumulating specific human capital would be the result of the high motivation of the individual, not of holding a permanent contract. To avoid such confounding issues in our analysis, it is essential to control for a vast array of potential factors which simultaneously affect the respective outcome variables (i.e., both variables related to training activities as well as the skills competence variables) and the treatment variable (in our case, the type of contract).

To do so we present in the next section the estimates obtained in several econometric models which include two types of controls. First, we use the individuals' basic characteristics such as age, gender, educational attainment, marital status, whether they have children, immigrant 
status, and parental educational background. In addition, we will also control for a potentially key variable which often is not available in other datasets but which PIAAC reports. This is the degree of worker's motivation, measured by a dummy variable, denoted as motivation, which takes the value 1 when the individual claims to feel identified "to a great extent" or "to a very great extent" with learning new skills, with working out difficult tasks, with relating new things to what they already know, and with seeking more information when they do not understand something". Secondly, in some specifications we also control for occupational dummies (as measured by the ISCO08 classification to two digits), industry dummies (as measured by the one-digit classification from the fourth ISIC revision) as well as having a part-time job.

In addition to standard regression models, in this paper we follow a second approach which involves controlling for selection in observables using propensity score matching techniques (PSM). In our setup, PSM involves matching each individual holding a temporary contract with one or more individuals who hold permanent contracts but who are similar in all other observable characteristics to a temporary worker. In this way, we effectively create matched "treatment" and "control" samples who hold temporary and permanent contracts being identical in every other observable respect (Rosenbaum and Rubin, 1983). If matching is sufficiently good, differences in mean outcomes (e.g., OJT availability and intensity, cognitive scores) may be used as estimates of the causal effect of holding a temporary contract. As is well known, one advantage of PSM over regression analysis is that it is non-parametric instead of imposing functional form restrictions, such as linearity on the outcome equations.

\section{EMPIRICAL RESULTS}

\subsection{Regression models}

The first set of results concerning regression models is reported in Table 2. They are expressed in terms of marginal effects and correspond to the estimation by maximum likelihood of a probit model to explain the probability of receiving training at the workplace $\left(D^{\text {OJT}=1)}\right.$ depending on our variable of interest, temporary contract, plus a wide array of controls.

In column [1], we present the results in the case when type of contract is the only covariate in the probit model. In column [2], job tenure, worker's age and its square (as a proxy for potential experience, given the higher educational level reached), gender (female $=1$ ) and educational level (with a low level as the reference category) are included as additional covariates. In column [3], the previous group of controls is extended by also including dummy variables of the parents' educational level, marital status, immigrant status and the degree of motivation of the worker. In column [4], dummy variables of sector/industry and occupation are also added. Finally in column [5], which constitutes the more general specification of the probit model, the literacy and numeracy scores contained in PIAAC are included as additional 
proxies of unobserved ability before training. ${ }^{7}$ For convenience, this ordering by columns, from the most restrictive specification to the most general, is kept for the rest of Tables to be presented in this section. It is also important to note that the number of observations in the different specifications varies slightly because some controls are not available for all individuals analyzed in the larger samples.

Table 2. Probit Model (Marginal Effects). Dependent variable: $D^{\text {OJT }}$

\begin{tabular}{|c|c|c|c|c|c|}
\hline & [1] & [2] & [3] & [4] & [5] \\
\hline \multirow[t]{2}{*}{ Temporary contract } & $-0.1636 * * *$ & $-0.0923 * * *$ & $-0.0795 * * *$ & $-0.0774 * * *$ & $-0.0732 * * *$ \\
\hline & $(0.0223)$ & $(0.0265)$ & $(0.0284)$ & $(0.0306)$ & $(0.0302)$ \\
\hline \multirow[t]{2}{*}{ Job tenure } & --- & $0.0053^{* * *}$ & $0.0049 * * *$ & $0.0035^{* *}$ & $0.0037^{* *}$ \\
\hline & & $(0.0014)$ & $(0.0015)$ & $(0.0016)$ & $(0.0015)$ \\
\hline \multirow{2}{*}{ Age } & --- & $0.0132 *$ & $0.0179 * *$ & $0.0150^{*}$ & $0.01460 *$ \\
\hline & & $(0.0071)$ & $(0.0084)$ & $(0.0088)$ & $(0.0088)$ \\
\hline \multirow{2}{*}{$(\text { Age })^{2} / 100$} & --- & $-0.0002 * *$ & $-0.0002 * *$ & $-0.0002 * *$ & $-0.0002 * *$ \\
\hline & & $(0.0001)$ & $(0.0001)$ & $(0.0001)$ & $(0.0001)$ \\
\hline \multirow[t]{2}{*}{ Female } & --- & $-0.0359 *$ & $-0.0376^{*}$ & -0.0117 & -0.0098 \\
\hline & & $(0.0205)$ & $(0.0219)$ & $(0.0270)$ & $(0.0268)$ \\
\hline \multirow[t]{2}{*}{ Middle educational level } & --- & $0.1279 * * *$ & $0.1359 * * *$ & $0.0947 * * *$ & $0.0899 * * *$ \\
\hline & & $(0.0286)$ & $(0.0305)$ & (0.0329) & $(0.0315)$ \\
\hline \multirow[t]{2}{*}{ High educational level } & --- & $0.2731 * * *$ & $0.2550 * * *$ & $0.1578^{* * *}$ & $0.1479 * * *$ \\
\hline & & $(0.0227)$ & $(0.0258)$ & $(0.0328)$ & $(0.0330)$ \\
\hline Educational level of parents & No & No & Yes & Yes & Yes \\
\hline Civil status, children & No & No & Yes & Yes & Yes \\
\hline Immigrant & No & No & Yes & Yes & Yes \\
\hline Motivation & No & No & Yes & Yes & Yes \\
\hline $\begin{array}{l}\text { Dummies by Sector and } \\
\text { Occupation }\end{array}$ & No & No & No & Yes & Yes \\
\hline $\begin{array}{l}\text { Literacy/Numeracy } \\
\text { scores }\end{array}$ & No & No & No & No & $\begin{array}{l}\text { Yes } \\
\text { Yes }\end{array}$ \\
\hline No. obs. & 2503 & 2501 & 2258 & 2206 & 0.104 \\
\hline Pseudo R-sq. & 0.015 & 0.065 & 0.074 & 0.102 & 0.104 \\
\hline Prob. obs. & 0.4371 & 0.4374 & 0.4353 & 0.4424 & 0.4424 \\
\hline \multicolumn{6}{|c|}{$\begin{array}{l}\text { Note: The marginal effects of the dichotomous variables are calculated as the change of the estimation of the probability when the variable } \\
\text { changes from } 0 \text { to } 1 \text {. Temporary contract variable is an indicator variable which takes the value } 0 \text { when the individual has a permanent } \\
\text { contract and } 1 \text { when he/she has a temporary contract. Job tenure measures the duration of the current job. Middle educational level is a } \\
\text { dichotomous variable which takes value } 1 \text { when an individual has vocational training at an intermediate level, the baccalaureate, or old } \\
\text { higher baccalaureates and pre-university courses. High educational level takes a value of } 1 \text { when the individual has a tertiary education } \\
\text { degree. The variables about the educational level of the parents are dichotomous variables for the three levels of education. Civil status } \\
\text { reflects whether the individual is married, children reflects whether they have children, and immigrant reflects whether the individual was } \\
\text { born in this country. The motivation variable takes the value } 1 \text { when the individual claims to feel "greatly" or "very greatly" identified with the } \\
\text { learning of new skills, working out difficult tasks, relating new things to what they already know, and looking for information when they don't } \\
\text { understand something. In column [4]., the variables of occupation are obtained from the IICOO8 to two digits while the variables of sector } \\
\text { are obtained with the one-digit classsification from the fourth ISIC revision. In column [5], Literacy and Numeracy scores are obtained from } \\
\text { PIAAC. Levels of significance: }{ }^{*} p<0.10,{ }^{* \star} p<0.05,{ }^{* \star *} p<0.01\end{array}$} \\
\hline
\end{tabular}

\footnotetext{
7 Despite the fact that these scores are measured at the time of the survey and that, as shown below, they are endogenous (since they are affected by OJT which itself depends on holding a temporary contract), we use them in column [5] to check that the results reported in columns [2] to [4] are fairly robust to the inclusion of scores.
} 
The main result in Table 2 is that, in line with our hypothesis, the estimated coefficient on the temporary contract dummy variable is negative and highly statistically significant in all specifications. Furthermore, the estimates suggest that the marginal effect is quantitatively very relevant. In the absence of further controls (column [1]), having a temporary contract is associated with a reduction in the probability of receiving OTJ of 16.4 percentage points (pp.), where the baseline probability of receiving OTJ among permanent workers is $43.7 \%$. By progressively adding further covariates, the estimated marginal effect is halved, falling to about 8-9 percentage points, a result which is fairly robust across columns [2] to [5]. ${ }^{8}$ Therefore, from this evidence one can infer that the detrimental effect of contractual instability on the specific training received in the workplace is substantial. For example, the marginal effects reported in the most extended specifications (columns [4] and [5]) imply that, for the typical worker with a permanent contract, switching to a temporary contract reduces the probability of receiving training at the workplace by between $17 \%$ and $18 \%(=-0.077 / .437)$.

With respect to the other controls, it is worth pointing out that a higher educational level increases the probability of receiving OJT and also that this probability also increases with age up to a threshold of about 30 years due to the concave shape of the quadratic polynomial for this variable. Furthermore, although statistically less significant than the above-mentioned estimates, there is evidence about women having a lower probability of receiving OJT, although this gender effect disappears as the number of controls in columns [3] and [4] is extended. In this regard it should be pointed out that, as mentioned earlier, another variable (not reported in Table 2) which has been included in all the specifications is whether the individual has a part-time job (where the reference category is full-time work). Its inclusion did not change any of the previous results, either in this Table or in any of those shown further below, but it did cancel out the above-mentioned gender effect. This is probably due to the high incidence of part-time working schemes among female employees, making it impossible to identify whether the relevant covariate is gender or working part time. Finally, although not reported to save space, the variables of immigrant status and motivation proved to be significant in columns [2] and [3], with negative and positive signs, respectively. However, the effect of motivation becomes weaker on adding the set of occupational and industry dummy variables.

We next report in Table 3 the results from estimating the coefficients of a count data model based on the Negative Binomial distribution (which is used after rejecting the equality of mean and variance implied by the more restrictive Poisson distribution), in order to detect the discrete nature of the dependent variable, namely, the number of training activities which the worker has attended over the past 12 months, $n^{\text {OJT }}$.

\footnotetext{
${ }^{8}$ We also included an interaction term between Temporary contract and being younger than 30 years old. In this case the marginal effects are $-0.1191(0.0463)$ for younger workers and $-0.0504(0.0346)$ for older ones. However, a chi-square test cannot reject the null hypothesis that these marginal effects are the same ( $p$-value $=0.213)$.
} 
Table 3. Binomial Negative Model (Coefficients). Dependent variable: $n^{\text {OJT }}$

\begin{tabular}{|c|c|c|c|c|c|}
\hline & [1] & [2] & [3] & [4] & [5] \\
\hline \multirow[t]{2}{*}{ Temporary contract } & $-0.1999 * * *$ & $-0.1666 * *$ & $-0.14845^{* *}$ & $-0.1299 *$ & $-0.1197^{*}$ \\
\hline & $(0.0512)$ & $(0.0614)$ & $(0.0684)$ & $(0.0709)$ & $(0.0701)$ \\
\hline \multirow[t]{2}{*}{ Job tenure } & --- & $0.0076^{*}$ & 0.0052 & 0.0049 & 0.0045 \\
\hline & & (0.0039) & $(0.0041)$ & $(0.0043)$ & $(0.0044)$ \\
\hline \multirow[t]{2}{*}{ Age } & --- & -0.0152 & $-0.0417^{*}$ & -0.0109 & -0.0223 \\
\hline & & (0.0193) & $(0.0231)$ & $(0.0236)$ & $(0.0241)$ \\
\hline \multirow[t]{2}{*}{$(\text { Age })^{2} / 100$} & --- & 0.0066 & 0.00401 & 0.0043 & 0.0041 \\
\hline & & (0.0239) & $(0.0277)$ & $(0.0281)$ & $(0.0279)$ \\
\hline \multirow[t]{2}{*}{ Female } & --- & -0.0144 & -0.0367 & $-0.1367 * *$ & $-0.1158^{*}$ \\
\hline & & $(0.0543)$ & $(0.0576)$ & $(0.0657)$ & $(0.0651)$ \\
\hline \multirow[t]{2}{*}{ Middle educational level } & --- & 0.0574 & -0.014 & -0.0645 & -0.0612 \\
\hline & & $(0.0846)$ & $(0.0900)$ & $(0.0923)$ & (0.0899) \\
\hline \multirow[t]{2}{*}{ High educational level } & --- & $0.2234 * * *$ & 0.0954 & 0.0942 & 0.0899 \\
\hline & & $(0.0688)$ & $(0.0769)$ & (0.0906) & $(0.0912)$ \\
\hline Educational level of parents & No & No & Yes & Yes & Yes \\
\hline Civil status, children & No & No & Yes & Yes & Yes \\
\hline Immigrant & No & No & Yes & Yes & Yes \\
\hline Motivation & No & No & Yes & Yes & Yes \\
\hline Dummies by Sector and Occupation & No & No & No & Yes & Yes \\
\hline Literacy/Numeracy scores & No & No & No & No & Yes \\
\hline \multirow[t]{2}{*}{ Dispersion Coefficient } & $-0.8518 * * *$ & $-0.8766 * * *$ & $-0.8999 * * *$ & $-1.1637 * * *$ & $-1.2357 * * *$ \\
\hline & $(0.0689)$ & $(0.0695)$ & $(0.0736)$ & $(0.0823)$ & $(0.0807)$ \\
\hline No. obs. & 1092 & 1092 & 981 & 974 & 974 \\
\hline Pseudo R-squared & 0.001 & 0.005 & 0.015 & 0.056 & 0.058 \\
\hline
\end{tabular}

As can be inspected, the results for our variable of interest, temporary contract, are similar to those obtained in Table 2, in the sense that this covariate systematically exhibits a negative sign, indicating again that holding a temporary contract reduces the number of OJT activities. However, unlike what happened in the probit model for $D^{O J T}$, the estimated coefficient on this variable is only statistically significant at the 10 percent level when all the controls are included. This may be due to the small number of individuals who report this information (around 1000), representing less than half the sample size used in the probit model.

Finally, in Table 4 we present the results of estimating another probit model, this time applied to explaining the probability associated with the dummy variable on the need of a higher level of training, more $e^{O J T}$. Although the estimated marginal effect of temporary contract is positive in all cases, it is statistically significant only in column [1]. In agreement with our previous discussion, this lack of statistical significance could be due to the fact that some of the additional controls (especially the educational level or the dummies of occupation and sector) may be detecting the potential mismatch between the training of the individual and the job requirements in a much more accurate way than the type of contract the individual holds. 
Table 4. Probit Model (Marginal Effects). Dependent variable: more $e^{\text {OJT }}$

\begin{tabular}{|c|c|c|c|c|}
\hline & [1] & [2] & [3] & [4] \\
\hline \multirow[t]{2}{*}{ Temporary contract } & $0.0532 * *$ & 0.0168 & 0.0148 & 0.0175 \\
\hline & $(0.0225)$ & $(0.0260)$ & $(0.0276)$ & $(0.0295)$ \\
\hline \multirow[t]{2}{*}{ Job tenure } & --- & 0.0016 & 0.002 & 0.0011 \\
\hline & & $(0.0013)$ & $(0.0014)$ & $(0.0015)$ \\
\hline \multirow[t]{2}{*}{ Age } & --- & $0.0210 * * *$ & $0.0201 * *$ & $0.0215^{* * *}$ \\
\hline & & $(0.0067)$ & $(0.0080)$ & $(0.0083)$ \\
\hline \multirow[t]{2}{*}{$(\text { Age })^{2} / 100$} & --- & $-0.0003 * * *$ & $-0.0003^{* * *}$ & $-0.0003 * * *$ \\
\hline & & $(0.0001)$ & $(0.0001)$ & $(0.0001)$ \\
\hline \multirow[t]{2}{*}{ Female } & --- & -0.0209 & -0.0251 & 0.0126 \\
\hline & & (0.0197) & $(0.0210)$ & $(0.0259)$ \\
\hline \multirow[t]{2}{*}{ Middle educational level } & --- & $0.0807 * * *$ & $0.0749 * *$ & 0.0483 \\
\hline & & $(0.0282)$ & $(0.0300)$ & (0.0319) \\
\hline \multirow[t]{2}{*}{ High educational level } & --- & $0.1588^{* * *}$ & $0.1492^{* * *}$ & $0.0685^{* *}$ \\
\hline & & $(0.0228)$ & $(0.0257)$ & $(0.0321)$ \\
\hline Educational level of parents & No & No & Yes & Yes \\
\hline Civil status, children & No & No & Yes & Yes \\
\hline Immigrant & No & No & Yes & Yes \\
\hline Motivation & No & No & Yes & Yes \\
\hline Dummies by Sector and Occupation & No & No & No & Yes \\
\hline No. obs. & 2508 & 2506 & 2262 & 2235 \\
\hline Pseudo R-sq. & 0.002 & 0.023 & 0.025 & 0.071 \\
\hline Prob. obs. & 0.3792 & 0.3795 & 0.382 & 0.3834 \\
\hline 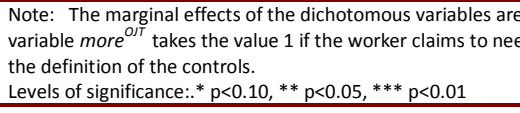 & & perform his/he & $\begin{array}{l}\text { he caseof a change } \\
s \text { and } 0 \text { if otherwise }\end{array}$ & $\begin{array}{l}\text { ariable from o to } 1 \text {. Th } \\
\text { e note from Table } 2 \text { fo }\end{array}$ \\
\hline
\end{tabular}

A brief summary of the main findings reported so far indicates that holding a temporary contract exhibits a negative relationship with the first two outcome variables (training availability and intensity) we have considered. However, there is no evidence that temporary workers demand more training than permanent workers, possibly due to the lower skill requirement of temporary jobs. Moreover, the finding that the estimated relationship is more robust to model specification when the dependent variable is $D^{O J T}$ may be due to the smaller measurement error of this outcome variable than the other two.

In view of these results, the next step is to check whether the availability or the intensity of OJT activities has an effect on the scores obtained by the individuals in the PIAAC literacy and numeracy tests. Tables 5 and 6 , respectively, present the results derived from estimating a linear regression model by OLS, where the outcome variables are the scores and the variables of interest are the two measurements of OJT for which a stronger relationship to temporary contract has been found, namely $D^{O J T}$, and to a lesser extent, $n^{O J T}$. Note that in both models the temporary contract treatment variable is not included as a regressor in order to test whether the effect of this variable on the scores is mainly brought about through the amount of OTJ received at the workplace, and not directly. 
Table 5. Ordinary Least Squares (Coefficients). Dependent variable: Literacy scores.

\begin{tabular}{|c|c|c|c|c|}
\hline & [1] & [2] & [3] & [4] \\
\hline \multirow[t]{2}{*}{$D^{\text {OJT }}$} & $3.5467 * *$ & --- & 2.072 & 1.2566 \\
\hline & (1.5939) & & (1.6009) & $(1.6095)$ \\
\hline \multirow[t]{2}{*}{$n^{\text {OJT }}$} & --- & $0.5380 * *$ & --- & --- \\
\hline & & $(0.2557)$ & & \\
\hline \multirow[t]{2}{*}{ Job tenure } & $0.2672 * *$ & $0.3766 * *$ & 0.1667 & 0.0734 \\
\hline & $(0.1059)$ & $(0.1727)$ & $(0.1085)$ & (0.1119) \\
\hline \multirow[t]{2}{*}{ Age } & $2.6996 * * *$ & $2.6412 * * *$ & $3.4779 * * *$ & $3.6443 * * *$ \\
\hline & $(0.5096)$ & $(0.8166)$ & $(0.5709)$ & $(0.5850)$ \\
\hline \multirow[t]{2}{*}{$(\text { Age })^{2} / 100$} & $-4.2135^{* * *}$ & $-4.1243 * * *$ & $-4.9442 * * *$ & $-5.1794 * * *$ \\
\hline & $(0.6347)$ & $(1.0341)$ & $(0.6886)$ & $(0.7046)$ \\
\hline \multirow[t]{2}{*}{ Female } & $-9.2612 * * *$ & $-7.8979 * * *$ & $-7.4145^{* * *}$ & $-9.7869 * * *$ \\
\hline & $(1.5476)$ & $(2.3168)$ & $(1.5449)$ & $(1.9085)$ \\
\hline \multirow[t]{2}{*}{ Middle educational level } & $24.1234 * * *$ & $24.1112 * * *$ & $21.7160 * * *$ & $17.6391 * * *$ \\
\hline & $(2.2114)$ & $(3.6625)$ & $(2.2112)$ & $(2.3179)$ \\
\hline \multirow[t]{2}{*}{ High educational level } & $45.3710 * * *$ & $45.8212 * * *$ & $36.8107 * * *$ & $24.6992 * * *$ \\
\hline & $(1.8098)$ & $(2.8883)$ & $(1.9208)$ & $(2.2671)$ \\
\hline Educational level of parents & No & No & Yes & Yes \\
\hline Civil status, children & No & No & Yes & Yes \\
\hline Immigrant & No & No & Yes & Yes \\
\hline Motivation & No & No & Yes & Yes \\
\hline Dummies by Sector and Occupation & No & No & No & Yes \\
\hline No. obs. & 2807 & 1162 & 2536 & 2475 \\
\hline R-sq. & 0.250 & 0.219 & 0.295 & 0.327 \\
\hline
\end{tabular}

Tables 5 and 6 present the estimated coefficients in a regression where the dependent variable is literacy and numeracy, respectively. Columns [1] and [2] in both Tables differ in that $D^{O J T}$ is used as a covariate in the first column while $n^{O J T}$ is used in the second column. As can be inspected, the results indicate that both variables exhibit a positive relationship with scores in the PIAAC tests, though its statistical significance is low in the last two columns of Table 5. Furthermore, this estimated coefficient tends to be larger and statistically more significant in Table 6, where the relationship between $D^{O J T}$ and numeracy is examined. Hence, from the comparison of the estimates in both Tables with the raw differences reported in Table 1 between the PIAAC scores achieved by employees with and without OJT (14.2 pp. in literacy and $18.6 \mathrm{pp}$. in numeracy), we get that, ceteris paribus, the availability of such specific training activities account for $15 \%$ ( 2 pp.) and 28\% (5 pp.) of the raw score gaps in literacy and numeracy, respectively. 
Table 6. Ordinary Least Squares (Coefficients). Dependent variable: Numeracy scores.

\begin{tabular}{|c|c|c|c|c|}
\hline & [1] & [2] & [3] & [4] \\
\hline \multirow[t]{2}{*}{$D^{\text {OJT }}$} & $7.4523 * * *$ & --- & $5.7716 * * *$ & $3.7712 * *$ \\
\hline & $(1.6198)$ & & $(1.6325)$ & $(1.6500)$ \\
\hline \multirow[t]{2}{*}{$n^{\text {OJT }}$} & --- & 0.3888 & --- & --- \\
\hline & & $(0.2555)$ & & \\
\hline \multirow[t]{2}{*}{ Job tenure } & $0.3878 * * *$ & $0.3854 * *$ & $0.2628^{* *}$ & 0.1511 \\
\hline & $(0.1055)$ & $(0.1728)$ & (0.1094) & $(0.1135)$ \\
\hline \multirow[t]{2}{*}{ Age } & $2.5632 * * *$ & $3.1910 * * *$ & $3.1082 * * *$ & $3.2456 * * *$ \\
\hline & $(0.5295)$ & $(0.8415)$ & $(0.5917)$ & $(0.6103)$ \\
\hline \multirow[t]{2}{*}{$(\text { Age })^{2} / 100$} & $-4.1618 * * *$ & $-4.8786 * * *$ & $-4.6634 * * *$ & $-4.8173 * * *$ \\
\hline & $(0.6566)$ & $(1.0565)$ & $(0.7117)$ & $(0.7327)$ \\
\hline \multirow[t]{2}{*}{ Female } & $-16.9921 * * *$ & $-14.6935^{* * *}$ & $-16.3784 * * *$ & $-16.4630 * * *$ \\
\hline & $(1.5759)$ & $(2.3156)$ & $(1.5976)$ & $(1.9500)$ \\
\hline \multirow[t]{2}{*}{ Middle educational level } & $25.9530 * * *$ & $27.3051 * * *$ & $23.1693 * * *$ & $18.6021 * * *$ \\
\hline & $(2.2359)$ & (3.6899) & $(2.2672)$ & $(2.4043)$ \\
\hline \multirow[t]{2}{*}{ High educational level } & $48.1732 * * *$ & $48.5652 * * *$ & $39.9913 * * *$ & $27.4181 * * *$ \\
\hline & $(1.8621)$ & (3.0138) & $(1.9874)$ & $(2.3328)$ \\
\hline Educational level of parents & No & No & Yes & Yes \\
\hline Civil status, children & No & No & Yes & Yes \\
\hline Immigrant & No & No & Yes & Yes \\
\hline Motivation & No & No & Yes & Yes \\
\hline Dummies by Sector and Occupation & No & No & No & Yes \\
\hline No. obs. & 2807 & 1162 & 2536 & 2475 \\
\hline R-sq. & 0.288 & 0.247 & 0.322 & 0.35 \\
\hline
\end{tabular}

Therefore, our evidence suggests that the availability of training at the workplace and, to a lesser extent, the intensity of this training is associated with a significant improvement of workers' cognitive skills. In order to check if this correlation is mainly due to holding a temporary contract, this covariate is included in the previous specifications, in addition to the two training variables. The main result that we find (not reported in the Tables for sake of brevity) is that the coefficient on temporary contract is never significant and the estimated coefficients on $D^{O J T}$ and $n^{O J T}$ hardly experience any significant changes. ${ }^{9}$ Thus, we conclude that OJT plays an important role in explaining the PIAAC scores.

Next, Table 7 (dependent variable: literacy) and Table 8 (dependent variable: numeracy) report the estimated coefficients obtained from the reduced forms of the previous models in which the training variables are now replaced by the temporary contract covariate, to which the remaining array of controls are gradually added. The idea of these reduced forms is that, if the mechanism we explore is valid, we should expect that, ceteris paribus, being a temporary

\footnotetext{
${ }^{9}$ For example, the estimated coefficient on $D^{O J T}$ in most extended specification is 3.465 (s.e.: 1.69) whereas that on temporary contract is -00652 (s.e.: 0.11).
} 
worker has a negative effect on the scores mainly through the reduction of the amount of OJT they undertake, and not so much through other alternative channels. The results are supportive since the coefficients on temporary contract in all specifications are always negative and statistically significant, albeit only at the 10 percent level in columns [3] and [4].

Table7. Ordinary Least Squares (Reduced Form). Dependent variable: Literacy scores

\begin{tabular}{|c|c|c|c|c|}
\hline & [1] & [2] & [3] & [4] \\
\hline \multirow[t]{2}{*}{ Temporary contract } & $-6.5503 * * *$ & $-5.0915 * * *$ & $-4.9321 * *$ & $-4.0831 *$ \\
\hline & $(2.2086)$ & (2.1914) & $(2.3618)$ & $(2.2537)$ \\
\hline \multirow[t]{2}{*}{ Job tenure } & --- & $0.2758 * *$ & $0.1982^{*}$ & 0.0748 \\
\hline & & $(0.1174)$ & $(0.1204)$ & $(0.1236)$ \\
\hline \multirow[t]{2}{*}{ Age } & --- & $3.2708 * * *$ & $3.6018 * * *$ & $3.5278 * * *$ \\
\hline & & $(0.5666)$ & $(0.6226)$ & $(0.6257)$ \\
\hline \multirow[t]{2}{*}{$(\text { Age })^{2} / 100$} & --- & $-0.0479 * * *$ & $-0.0511 * * *$ & $-0.0505 * * *$ \\
\hline & & $(0.0070)$ & $(0.0075)$ & $(0.0075)$ \\
\hline \multirow[t]{2}{*}{ Female } & --- & $-8.3752 * * *$ & $-7.2715 * * *$ & $-9.6194 * * *$ \\
\hline & & $(1.6260)$ & $(1.6280)$ & $(1.9786)$ \\
\hline \multirow[t]{2}{*}{ Middle educational level } & --- & $22.3422 * * *$ & $21.6332 * * *$ & $17.4162^{* * *}$ \\
\hline & & $(2.3669)$ & $(2.3380)$ & $(2.4210)$ \\
\hline High educational level & --- & $42.0032 * * *$ & $37.3696 * * *$ & $24.7004 * * *$ \\
\hline Educational level of parents & No & No & Yes & Yes \\
\hline Civil status, children & No & No & Yes & Yes \\
\hline Immigrant & No & No & Yes & Yes \\
\hline Motivation & No & No & Yes & Yes \\
\hline Dummies by Sector and Occupation & No & No & No & Yes \\
\hline No. obs. & 2513 & 2447 & 2266 & 2244 \\
\hline R-sq. & 0.003 & 0.262 & 0.291 & 0.321 \\
\hline
\end{tabular}


Table 8. Ordinary Least Squares (Reduced Form). Dependent variable: Numeracy scores.

\begin{tabular}{|c|c|c|c|c|}
\hline & [1] & [2] & [3] & [4] \\
\hline \multirow[t]{2}{*}{ Temporary contract } & $-12.5522 * * *$ & $-4.5196 * *$ & $-3.8685^{*}$ & $-3.5884^{*}$ \\
\hline & $(2.2851)$ & $(2.2124)$ & $(2.2375)$ & $(2.2010)$ \\
\hline \multirow[t]{2}{*}{ Job tenure } & --- & $0.3751 * * *$ & $0.2631 * *$ & 0.1115 \\
\hline & & $(0.1190)$ & $(0.1217)$ & $(0.1253)$ \\
\hline \multirow[t]{2}{*}{ Age } & --- & $3.2379 * * *$ & $3.4562 * * *$ & $3.4258 * * *$ \\
\hline & & $(0.5779)$ & $(0.6392)$ & $(0.6438)$ \\
\hline \multirow[t]{2}{*}{$(\text { Age })^{2} / 100$} & --- & $-0.0486 * * *$ & $-0.0509 * * *$ & $-0.0503 * * *$ \\
\hline & & $(0.0071)$ & $(0.0077)$ & $(0.0077)$ \\
\hline \multirow[t]{2}{*}{ Female } & --- & $-15.8232 * * *$ & $-15.6563 * * *$ & $-15.7823 * * *$ \\
\hline & & $(1.6537)$ & $(1.6757)$ & $(2.0082)$ \\
\hline \multirow[t]{2}{*}{ Middle educational level } & --- & $23.6664 * * *$ & $22.8811 * * *$ & $18.3916 * * *$ \\
\hline & & $(2.3976)$ & $(2.3863)$ & $(2.4894)$ \\
\hline \multirow[t]{2}{*}{ High educational level } & --- & $44.2566 * * *$ & $40.2667 * * *$ & $27.2830 * * *$ \\
\hline & & $(2.0353)$ & $(2.0713)$ & $(2.3874)$ \\
\hline Educational level of parents & No & No & Yes & Yes \\
\hline Civil status, children & No & No & Yes & Yes \\
\hline Immigrant & No & No & Yes & Yes \\
\hline Motivation & No & No & Yes & Yes \\
\hline Dummies by Sector and Occupation & No & No & No & Yes \\
\hline No. obs. & 2513 & 2447 & 2266 & 2244 \\
\hline R-sq. & 0.012 & 0.289 & 0.313 & 0.345 \\
\hline
\end{tabular}


Finally, Table 9 reports further results about the effects of the extensive margin of OJT on PIAAC scores, this time using a restricted control group. Following the strategy proposed by Leuven and Oosterbeek (2008), which is used in OECD (2014), this new control group for workers who received OJT includes those employees who had the possibility to attend employer-sponsored training but ended up not doing so for exceptional and unexpected events. ${ }^{10}$ Specifically, PIAAC contains two questions that can be used for this purpose. First, all workers are asked whether during the prior 12 months there were any learning activities they wanted to attend but did not. Those answering affirmatively are then asked to indicate the reasons why they could not attend OJT. We use as control group those who declare that they could not attend because either "the course or programme was offered at an inconvenient time or place" or "something unexpected came up that prevented [them] from taking education or training". The treatment and control groups contain 1237 and 216 individuals, respectively. As can be observed, the estimates are qualitatively similar to those earlier reported in specification [4] of Tables 5 and 6 though smaller and statistically insignificant in the case of literacy scores.

Table 9. Ordinary Least Squares. Restricted sample. Dependent variables: Numeracy \& Literacy scores

\begin{tabular}{|l|c|c|}
\hline & Numeracy & Literacy \\
\hline$D^{\text {OJT }}$ & $2.341^{* *}$ & 1.121 \\
& $(1.213)$ & $(1.219)$ \\
No. obs. & 1453 & 1453 \\
R-sq. & 0.331 & 0.372 \\
\hline
\end{tabular}

Note: Both specifications include those workers who did receive on the job training over the last 12 months as treatment group and those who were offered training but did not take it either because of unexpected reasons or because the place and time of the course/ program were inconvenient. Additional controls are as in specification [4] in Tables 5 and 6 . Levels of significance: * $\mathrm{p}<0.10, * * \mathrm{p}<0.05, * * * \mathrm{p}<0.01$

\subsection{Propensity score matching}

We next present estimates of the relationship between temporary contract and OJT availability and numeracy scores using a PSM estimation method. For illustrative purposes, the reported results are restricted to these two outcome variables because they are the ones where the estimates presented above exhibited higher statistical significance. We use the nearest neighbour matching procedure which is available in the teffects Stata 11 command, because it

\footnotetext{
${ }^{10}$ We are grateful to Andrea Bassanini for pointing out to us that this procedure had been used in an Annex containing further material for chapter 4 of the OECD Employment Outlook (2014).
} 
computes more accurate standard errors than those computed by bootstrapping in other popular PSM estimation commands, as is the case of psmatch2 (see Abadie and Imbens, 2011). After imposing the common support condition, we report two estimates of interest that are provided by this command: the average treatment effect (ATE) and the average treatment effect on the treated (ATT).

To assess the quality of the matching, Table 10 presents the differences between the mean values of a subset of the covariates (occupational and industry dummies are not reported to save space) which are used to match the treatment (temporary contract, TC) and control (permanent contract, PC) groups.

Table 10. Quality of matching procedure. Treatment: Temporary contract

\begin{tabular}{|c|c|c|c|c|}
\hline & Treated & Control & $\%$ bias & $p$-value \\
\hline Tenure & 3.6482 & 3.6825 & -0.9 & 0.145 \\
\hline Age & 34.914 & 34.389 & 1.5 & 0.424 \\
\hline Age2 & 13.348 & 13.083 & 2.1 & 0.597 \\
\hline Female & 0.5335 & 0.5493 & -1.3 & 0.126 \\
\hline Deduc2 & 0.2178 & 0.2071 & 2.6 & 0.662 \\
\hline Deduc3 & 0.3214 & 0.2978 & 7.9 & 0.223 \\
\hline Deduc4 & 0.0071 & 0.0059 & 4.6 & 0.469 \\
\hline Married & 0.5214 & 0.5032 & 3.9 & 0.542 \\
\hline Children & 0.4464 & 0.4257 & 4.3 & 0.485 \\
\hline Immigrant & 0.2071 & 0.2136 & -3.0 & 0.244 \\
\hline Motivation & 0.4534 & 0.4732 & -4.1 & 0.313 \\
\hline$D f \_e d 2$ & 0.1517 & 0.1375 & 1.0 & 0.497 \\
\hline Df_ed3 & 0.1142 & 0.1071 & 2.3 & 0.704 \\
\hline Dm_ed2 & 0.1182 & 0.1092 & 8.2 & 0.417 \\
\hline Dm_ed3 & 0.0696 & 0.0864 & -6.7 & 0.195 \\
\hline
\end{tabular}

Note: Calculations performed with the teffects module in Stata 11. Statistics for the remaining controls considered in column (4) of Tables 2 and 8 have been omitted for brevity but are available upon request. 
Overall, the figures in Table 9 confirm that our treatment and comparisons, though initially different, appear to be rather similar after the matching, with no significant statistical differences in the means of the reported values and only two significant ones among the 42 background variables used in PSM. They correspond to two of the (omitted) occupational and industry dummies.

Finally, Table 11 displays the ATE (column 2) and ATT (column 3) estimates of the relationship between temporary contract and OJT availability $\left(D^{O J T}\right)$ and numeracy test scores using PSM estimation. For convenience we also append in column 1 the estimate of the marginal effect of temporary contract on $D^{\text {OJT }}$ appearing in Table 2, as well as the OLS estimate of the coefficient on such variable in the regression model for the numeracy score in Table 8. As can be observed, the PSM estimates are very similar to those presented before. Although they are slightly less significant than the probit/OLS ones, they point out to an unambiguously negative effect of holding a temporary contract on both outcome variables. In fact the ATE estimates are higher than the ATT and probit/OLS estimates, suggesting that to the extent that temporary contract has a causal effect on these two outcomes, that effect would be somewhat higher for individuals less likely to work under such a contract.

Table 11. Temporary contract, training availability and numeracy score

\begin{tabular}{|c|c|c|c|}
\hline & $\begin{array}{l}\text { [1] } \\
\text { Probit/OLS }\end{array}$ & $\begin{array}{c}\text { [2] } \\
\text { PSM:ATE }\end{array}$ & $\begin{array}{c}\text { [3] } \\
\text { PSM: ATT }\end{array}$ \\
\hline \multirow[t]{2}{*}{$D^{O J T}$} & $-0.0765^{* * *}$ & $-0.1035 * * *$ & $-0.0699 * *$ \\
\hline & $(0.0293)$ & $(0.0334)$ & $(0.0323)$ \\
\hline \multirow[t]{2}{*}{ Numeracy score } & $-3.5884^{*}$ & $-5.9952 * *$ & $-4.1304^{*}$ \\
\hline & $(2.2010)$ & $(2.5925)$ & $(2.6002)$ \\
\hline \multicolumn{4}{|c|}{$\begin{array}{l}\text { Note: Column } 1 \text { reports the probit marginal effects presented in in Table } 2 \text { whereas columns } 2 \text { and } 3 \text { show ATE and ATT-PSM estimates } \\
\text { including all the covariates in the most extensive specification as controls. We impose the common support condition using the teffects } \\
\text { Stata command which implements nearest-neighbour matching on an estimated propensity score. The standard errors implemented in } \\
\text { teffects psmatch are those derived by Abadie and Imbens (2012). Levels of significance:. }{ }^{*}<<0.10,{ }^{* *} p<0.05,{ }^{* * *} p<0.01\end{array}$} \\
\hline
\end{tabular}

Overall the results presented in this section are consistent with the basic prediction of our model. Temporary workers are significantly less likely to engage in OJT activities at the workplace that workers under permanent contracts, even after controlling for a wide array of individual and job characteristics which include workers' motivation. By contrast, temporary workers do not seem to differ from permanent workers in their perceptions regarding the appropriateness of their training with respect to the skills requirements in their current jobs. Finally, both the scores on literacy and numeracy skills are significantly lower for workers who 
receive less training. Moreover, among those who receive OJT, the scores are lower for those who receive less training.

\section{Cross-Country EU EVIDENCE ON OJT AND SKILls GAPS}

To provide further evidence on the validity of the mechanisms discussed in the previous two sections, we devote this section to report results for four EU reference countries about which PIAAC contains information on all the variables which have been used before in the empirical analysis carried out for Spain. These four countries are classified in two groups,

(I) France and Italy as two other examples of countries with dual labour markets but to a lesser extent than Spain.

(II) Denmark and the UK as examples of more unified labour markets where temporary contracts are used by firms as stepping stones to more stable jobs rather than as dead ends (see Booth et al, 2002).

In Panel A of Table 12 PIAAC-based information is reported for Spain (also included in group I) and the four reference countries concerning the following outcomes: (i) rates of temporary work, (ii) perm-temp gaps in the availability of OJT, (iii) perm-temp gaps in numeracy scores, and (iv) perm-temp gaps in literacy scores. Paralleling the discussion for the case of Spain, Panel B in turn displays the values of two main indicators of the degree of dualism in those countries: (i) the 2012 EPL gap between the mandated severance pay (in terms of weekly wages) of an unfair dismissal of a permanent worker with five years of tenure in a firm and the severance pay associated to hiring five temporary workers in sequence with a one-year contract each, and (ii) the temp-to perm conversion rates in 2010. To compute the EPL gap we have made use of the information provided in the Doing Business dataset of the World Bank (2013)-and the OECD (2013) dataset on severance pay, as well as of the results reported in Boeri et al (2013). For example, in 20012 the dismissal costs of an unfair dismissal of a permanent worker in Spain were 33 days of wages per year of service, so that after 5 years the total amount received by the worker would be 165 days of wages $(=5 \times 33)$. Each temporary worker was compensated with 10 days of wages per year of services for the non-renewal of her contract, so that the cost of the alternative strategy of hiring five temporary workers in sequence amounts to 50 days of wages $(=5 \times 10)$. Thus the EPL gap is 115 days of wages (16550) or about 16.6 weekly wages. As regards the temp-to-perm transition rates, they have been taken from Eichhorst (2013).

As can be observed in Panel A, countries in group $(\mathrm{I})$ tend to have slightly higher rates of temporary work than countries in group (II) but much higher perm-temp gaps in terms of OJT availability, being this gap even negative in the case of Denmark. The fact that the differential in OJT availability is high even when the rates of temporary work are not too dissimilar possibly reflects that temporary contracts in group (II) play the role of springboards to better jobs whereas they are often dead-end jobs in group (I). Countries in group (II) exhibit lower raw gaps in numeracy skills but higher gaps in literacy skills. Concerning set of indicators of labour 
market dualism, as expected, countries in group (II) have much lower EPL gaps and much higher temp-to- perm transition rates confirming the interpretation given above about the probation nature of temporary jobs in those countries.

Table 12. Outcomes and Indicators of Labour Market Dualism in EU reference countries

\begin{tabular}{|c|c|c|c|c|c|}
\hline \multirow[t]{2}{*}{ Panel A } & \multicolumn{5}{|c|}{ Outcomes $^{(a)}$} \\
\hline & Spain & France & Italy & Denmark & UK \\
\hline Rate of Temporary Employment (\%) & 27.5 & 17.0 & 22.1 & 16.6 & 20.2 \\
\hline OJT Gap (Perm - Temp) & 16.6 & 13.6 & 10.9 & -3.1 & 5.3 \\
\hline Literacy Score Gap (Perm - Temp) & 7.1 & 5.7 & 3.8 & 7.4 & 9.9 \\
\hline Numeracy Score Gap (Perm - Temp) & 14.1 & 11.8 & 7.1 & 2.9 & 5.2 \\
\hline \multirow[t]{2}{*}{ Panel B } & \multicolumn{5}{|c|}{ Indicators } \\
\hline & Spain & France & Italy & Denmark & UK \\
\hline EPL Gap (wkly. wages after 5 years) ${ }^{(b)}$ & 18.0 & 9.8 & 9.3 & 4.3 & 5.4 \\
\hline Temp-to-Perm Conversion Rate ${ }^{\text {(c) }}$ & 6.6 & 13.2 & 21.7 & 43.2 & 51.8 \\
\hline \multicolumn{6}{|c|}{ Notes: The term "Gap" always refer to the difference between workers with permanent and workers with temporary contracts. } \\
\hline \multicolumn{6}{|c|}{$\begin{array}{l}\text { (b) Gap in firing costs in weekly wages after } 5 \text { years of work in the event of a wrongful or unfair dismissal. Source: Doing Business WB (2013, OECD (2013) and Boeri, T. et } \\
\text { al. (2013). }\end{array}$} \\
\hline
\end{tabular}

Next, Table 13 presents the estimated coefficients for these countries of the temporary contract dummy on the four main outcome variables that were considered before: OJT availability $\left(D^{O J T}\right)$, OJT intensity $\left(n^{O J T}\right)$, Literacy score and Numeracy score. For comparative reasons we add the corresponding estimates for Spain in the first column of results. The specification considered is the one with the largest number of covariates.

As can be inspected, though Spain exhibits stronger results in general, there is a striking similarity with those obtained for France and Italy: having a temporary job has a negative and often statistically significant relationship with OJT and competences. By contrast, in Denmark and the UK holding a temporary contract does not have a detrimental effect on either outcome 
Table 13. Summary of Estimated Effects of Temporary Contracts on OJT and PIAAC scores

\begin{tabular}{|c|c|c|c|c|c|}
\hline Dependent Variable & Spain & France & Italy & Denmark & UK \\
\hline OJT availability $D^{O J T}$ & $-0.0774 * * *$ & $-0.0609 * * *$ & $-0.0494 * *$ & 0.0249 & -0.0120 \\
\hline & $(0.0306)$ & $(0.0244)$ & (0.0268) & $(0.0342)$ & $(0.0253)$ \\
\hline No. obs. & 2206 & 3156 & 2035 & 2718 & 4002 \\
\hline OJT intensity $n^{\text {OJT }}$ & $-0.1299 *$ & $-0.1034^{*}$ & $-0.2673 *$ & $0.1169 *$ & -0.0046 \\
\hline & (0.0709) & $(0.0574)$ & (0.1548) & $(0.0675)$ & $(0.0675)$ \\
\hline No. obs. & 974 & 873 & 506 & 1168 & 2124 \\
\hline Literacy Scores & $-4.0831 *$ & $-2.2708 *$ & $-3.6018 * *$ & 0.5237 & $1.2345^{*}$ \\
\hline & $(2.2357)$ & (1.3324) & $(1.7226)$ & $(0.3773)$ & $(0.6234)$ \\
\hline No. obs. & 2244 & 3325 & 2221 & 2891 & 4381 \\
\hline Numeracy Scores & $-3.5884 *$ & $-1.1479 *$ & $-2.2561 *$ & 0.3505 & 0.0987 \\
\hline & $(2.2110)$ & $(0.6022)$ & $(0.0075)$ & $(0.3876)$ & $(0.0742)$ \\
\hline No. obs. & 2244 & 3325 & 2221 & 2891 & 4381 \\
\hline
\end{tabular}

Finally, we end up by providing some evidence about selection into temporary contracts in the countries at hand. It has been argued earlier than these contracts are likely to be stepping stones in countries like Denmark or UK, and dead ends in the southern EU countries. This would mean that adult and older workers, say above 30, under temporary contracts are likely to be negatively selected in countries with more unified labour markets since their chances of reaching a permanent contract is high. By contrast, this will not be the case in dual labour markets where the probability of working under a temporary contract at 30-35 years of age is still substantial (about $40 \%$ against $90 \%$ at entry age in Spain). Thus, we should expect that workers above 30 would perform relatively worse in Denmark or UK than in the other countries. Table 14 reports raw gaps in Literacy and Numeracy scores between temps and perms. As can be seen, the gaps in the UK are particularly larger than in the southern EU countries and, though they are smaller in Denmark, they are larger than the corresponding gaps for the whole working age population reported in Table 12. Thus, overall we conclude that, in terms of OJT and proficiency, what really matters is not having a temporary contract per se, but rather holding a very precarious one because of the strong duality in employment protection. 
Table 14. Score Gaps by Labour Contract among Workers Older than $\mathbf{3 0}$ years of age

\section{Dependent variable}

\section{A. Literacy scores}

\begin{tabular}{|c|c|c|c|c|c|}
\hline & Spain & France & Italy & Denmark & UK \\
\hline \multirow[t]{2}{*}{ Temporary contract } & $-12.56^{\star \star \star}$ & $-12.76^{\star \star \star}$ & $-11.73^{\star \star \star}$ & $-8.18^{*}$ & $-14.83^{\star \star \star}$ \\
\hline & (2.85). & (3.17) & (3.11) & $(5.00)$ & $(2.36)$ \\
\hline \multirow[t]{2}{*}{ Constant } & $261.00^{\star \star \star}$ & $266.17^{\star \star \star}$ & $261.8^{\star \star \star}$ & $275.16^{\star \star \star}$ & $280.88^{\star \star \star}$ \\
\hline & (1.18) & $(0.91)$ & (1.10) & $(0.76)$ & $(0.82)$ \\
\hline No. obs. & 1990 & 2994 & 1749 & 2423 & 3503 \\
\hline
\end{tabular}

\section{B. Numeracy scores}

\begin{tabular}{|c|c|c|c|c|c|}
\hline & Spain & France & Italy & Denmark & UK \\
\hline Temporary contract & $-16.23^{\star \star \star}$ & $-17.53^{\star \star \star}$ & $-10.26^{\star \star \star}$ & $-7.183^{*}$ & $-17.58^{\star \star \star}$ \\
\hline & $(2.92)$ & (3.70) & (3.52) & $(4.22)$ & $(2.61)$ \\
\hline Constant & $258.90^{\star \star \star}$ & $262.33^{\star \star \star}$ & $262.59^{\star \star *}$ & $286.47^{\star \star \star}$ & $273.88^{\star \star \star}$ \\
\hline & $(1.21)$ & (1.07) & (1.24) & (0.84) & (0.91) \\
\hline No. obs. & 1990 & 2994 & 1749 & 2423 & 3503 \\
\hline
\end{tabular}




\section{CONCLUSIONS}

We began this paper by observing that, over the last few decades, the Spanish labour market has been characterized by its extreme dualism and by the low fraction of workers, especially temporary ones, that receive firm-provided training. On the basis of these considerations, our goal here is to analyze how the gap in employment protection between permanent and temporary workers may have affected the extensive and intensive margins of the OJT that different types of employees receive at the workplace.

To address this issue, we first illustrate, by means of a simple theoretical model the mechanism linking labour-market dualism to the deficiency in the training of temporary workers. We show that, in a context where wages are not flexible enough and the dismissal cost gap between permanent and temporary workers is so high that firms are not inclined to convert unstable contracts into stable ones, employers have few incentives to invest in training their temporary workers. As a result, this underinvestment may have negative consequences over the skills competences that workers acquire at the workplace.

The cross-sectional database for Spain provided by PIAAC allows us to explore these issues. Specifically, the availability of several different OJT measures, as well as workers' scores on literacy and numeracy tests, allows us to check, firstly, the direct relation between the type of contract held by workers and the amount of OJT they receive and, secondly, whether this type of training affects cognitive skills.

We present econometric results for several outcome variables: two measures of training activities (availability and intensity), a measure of workers' perceptions on the need of greater and better OTJ, and two measures of cognitive skills. For each econometric model (including propensity score matching estimation), we report results using different specifications. In our broader specification we consider (in addition to the temporary contract indicator) a wide set individual demographics, including proxy variables of the workers' family background, ability and motivation, and job characteristics.

Our main empirical findings support in general our basic hypotheses, namely the existence of a negative relationship between job instability and training at the workplace, as well as a positive relationship between the amount/intensity of OJT activities and workers' cognitive skills. Furthermore, the previous detrimental results seem to hold for other two EU reference countries (France and Italy) which, like Spain, also have highly segmented labour markets. By contrast, they turn out not to be detrimental in another two countries with more unified labour markets, where much lower EPL gaps imply that temporary contracts are mostly stepping stones towards more stable jobs rather than dead-ends.

Although the cross-sectional nature of PIAAC makes it difficult to derive neat causal statements from such results, the evidence we provide is however suggestive that the proposed mechanism may have played a role in explaining the previous facts. 


\section{REFERENCES}

Abadie, A., and G. W. Imbens (2008): "On the Failure of the Bootstrap for Matching Estimators. Econometrica 76: 1537--1557.

Abadie, A., and G. W. Imbens (2012): "Matching on the Estimated Propensity Score". Harvard University and NBER. http://www.hks.harvard.edu/fs/aabadie/pscore.pdf.

Acemoglu, D. and J-S. Pischke (1999): "The Structure of Wages and Investment in General Training", Journal of Political Economy, 107, 539-572.

Alba-Ramirez, A. (1994): "Formal Training, Temporary Contracts, Productivity and Wages in Spain," Oxford Bulletin of Economics and Statistics, 56(2), 151--170.

Alonso-Borrego, C. (2010), "Firm Behaviour, Market Deregulation and Productivity in Spain ", Banco de España, Documento de Trabajo 1035.

Amuedo-Dorantes, C. (2001): "From "temp-to-perm": Promoting Permanent Employment in Spain," International Journal of Manpower, 22(7), 625--647.

Arulampalam, W., Booth, a. and M. Bryan (2004): "Training in Europe," Journal of the European Economic Association, 2, 346-360.

Bassanini, A., L. Nunziata, and D. Venn (2009): "Job Protection Legislation and Productivity Growth in OECD Countries," Economic Policy, 24, 349-402.

Bentolila, S., Dolado, J. and J. F. Jimeno (2008): Two-tier Employment Protection Reforms: The Spanish Experience" CES-Ifo-DICE, Journal for International Comparisons (2008), 6, 49-56.

Bentolila, S., P. Cahuc, J. Dolado, and T. Le Barbanchon (2012): "Two-Tier Labour Markets in a Deep Recession: France vs. Spain," The Economic Journal, 122, 155-187.

Boeri, T., Garibaldi, P. and E. Moen (2013): “The Economics of Severance Pay,” IZA DP No. 7455.

Booth, A., Francesconi, M. and J. Frank (2002): "Temporary Jobs: Stepping Stones or Dead Ends?" The Economic Journal,112, F189-F213.

Cahuc, P. and F. Postel-Vinay (2002): Temporary Jobs, Employment Protection and Labor Market Performance," Labour Economics, 9, 63-91.

De la Rica, S., J. Dolado, and V. Llorens (2008): "Ceilings or Floors? Gender Wage Gaps by Education in Spain," Journal of Population Economics, 21, 751--776.

Dolado, J., C. Garcia-Serrano, and J. F. Jimeno (2002): Drawing Lessons From The Boom Of Temporary Jobs In Spain," The Economic Journal, 112(721), 270--295.

Dolado, J., Ortigueira, S. and R. Stucchi (2013): " Does Dual Employment Protection affect TFP? Evidence from Spanish Manufacturing Firms", mimeo, Universidad Carlos III de Madrid.

Eichhorst, W (2013): "The Unequal Distribution of Labor Market Risks: Permanent vs. Temporary Employment”, IZA, http://www.iza.org/conference_files/EULaMaFuEm_2013/eichhorst_w2291.pdf

Escribá, J. and M.J. Murgui (2009): "Regional Aspects of the Productivity Slowdown: An Analysis of Spanish Sectorial Data from 1980 to 2003", SGPC WP. 2009-03.

European Commision (2014): EU Skills Panorama. Brussels. 
Fifth European Working Conditions Survey (2010). http://www.eurofound.europa.eu/surveys/ewcs/2010/

Garda, P. (2013): "Wage Losses after Displacement in Spain: The Role of Specific Human Capital," mimeo, Universitat Pompeu Fabra.

González, X. and D. Miles (2012): "Labor Market Rigidities and Economic Efficiency: Evidence from Spain," Labour Economics, 20 (6), 833-45.

Güell, M. and B. Petrongolo (2007): "How Binding are Legal Limits? Transitions from Temporary to Permanent Work in Spain," Labour Economics, 14, 153--183.

Lapage-Saucier, N., Schleich, J. and E. Wasmer (2013): “Moving Toward a Single Labour

Contract: Pros, Cons and Mixed Feelings," OECD Economics Dept. Working Paper No. 1026.

Leuven, E. and H. Oosterbeek (2008): "An alternative approach to estimate the wage returns to work-related training. Journal of Applied Econometrics, 23, 423-434.

OECD (2013): “Employment Protection Legislation, 2012-2013,” OECD EPL database

OECD (2014): Employment Outlook. Chapter 4: Non Regular Employment, Job Security and the Labour Market Divide.

Rosembaum, P. and D.B. Rubin (1983): "The Central role of the Propensity Score in Observational Studies for Causal Effects," Biometrika, 70, 41-55.

Sanchez, R., and L. Toharia (2000): "Temporary Workers and Productivity: The Case of Spain," Applied Economics, 32, 583--591.

World Bank (2013): “Employing Workers Data", Doing Business Indicators. 


\section{APPENDIX}

\section{(INTEGRATION by PARTS)}

For illustrative purposes, let us consider the case of a trained worker under a $\mathrm{P}$ contract where we use the notation $R=w-F$ for the productivity cutoff when a shock hits. Then

$$
\begin{aligned}
& W_{P}^{t}(\varepsilon, \zeta)=\theta-C(\theta)+\left[\int_{\bar{\zeta}(1-\varepsilon)}^{\bar{\zeta}} \max (\zeta-w,-F) d G_{\zeta}(\varepsilon)\right]= \\
& =\theta-C(\theta)+\left[\int_{\bar{\zeta}(1-\varepsilon)}^{\bar{\zeta}} \max (\zeta-w+F, 0) d G_{\zeta}(\varepsilon)-F \int_{\bar{\zeta}(1-\varepsilon)}^{\bar{\zeta}} d G_{\zeta}(\varepsilon)\right] \\
& =\theta-C(\theta)+\left[\int_{\bar{\zeta}(1-\varepsilon)}^{\bar{\zeta}} \max (\zeta-w+F, 0) d G_{\zeta}(\varepsilon)-F\right] \\
& =\theta-C(\theta)+\left[\int_{R}^{\bar{\zeta}}(\zeta-w) d G_{\zeta}(\varepsilon)+F \int_{R}^{\bar{\zeta}} d G_{\zeta}(\varepsilon)-F\right] \\
& =\theta-C(\theta)+\left[\int_{R}^{\bar{\zeta}}(\zeta-w) d G_{\zeta}(\varepsilon)-F G_{\zeta}(R)\right]
\end{aligned}
$$

Then, integration by parts for the term $\int_{R}^{\bar{\zeta}}(\zeta-w) d G_{\zeta}(\varepsilon)$ yields

$$
\begin{aligned}
& W_{P}^{t}(\varepsilon, \zeta)=\theta-C(\theta)+\left[\left(\bar{\zeta}-w_{P}\right)-(R-w) G_{\zeta}(R)\right]-\int_{R}^{\bar{\zeta}} G_{\zeta}(\varepsilon) d \zeta-F G_{\zeta}(R)= \\
& =\theta-C(\theta)+(\bar{\zeta}-w)-\int_{R}^{\bar{\zeta}} G_{\zeta}(\varepsilon) d \zeta
\end{aligned}
$$

where the last equality follows from $\left(R-w_{P}\right) G_{\zeta}(R)=-F G_{\zeta}(R)$. 